\title{
O MÉTODO DA ANÁLISE DOCUMENTAL: SEU USO NUMA PESQUISA HISTORIOGRÁFICA
}

\author{
ALESSANDRA PIMENTEL \\ Departamento de Psicologia Social e Institucional da Universidade \\ Estadual de Londrina - PR \\ alessapimen@ig.com.br
}

\begin{abstract}
RESUMO
Com o intuito de contribuir para a utilização de análise documental em pesquisa, este texto apresenta o processo de uma investigação que objetivou compreender as relaçóes entre psicologia e educação, no contexto sócio-histórico brasileiro, entre as décadas de 50 e 80. Partindo de uma autora cuja relevância na história recente se deve, especialmente, à criação de uma proposta de alfabetização, o Programa Alfa, foram pesquisadas as intersecções entre produção teórica da psicologia e atividade prática em educação. São descritos os instrumentos e meios de realização da análise de conteúdo, apontando o percurso em que as decisóes foram sendo tomadas quanto às técnicas de manuseio dos documentos: desde a organização e classificação do material até a elaboração das categorias de análise. A perspectiva historiográfica adotada nesse estudo procurou superar a dicotomia entre as abordagens internalista e externalista da história das ciências, propiciando compreender o âmbito sóciohistórico em que se constituiu a referida produção científica.
\end{abstract}

PSICOLOGIA-EDUCAÇÃO_PROGRAMAALFA-METODOLOGIADEPESQUISA-ANÁLISE DECONTEÚDO

\section{ABSTRACT}

THEMETHOD OFTHEDOCUMENTAL ANALYSIS: THEUSEFORAHISTORIOGRAPHYCAL RESEARCH. With intention to contribute for the use of the documentary analysis in research, this text presents the process of execution of an inquiry that aimed at to understand the relationships between psychology and education, into the context of the workmanship of an author - whose relevance in recent history is owing, especially, to the creation of a literacy proposal, the Programa Alfa - it was investigated the interchange between theoretical production from psychology and practical activity in education. The instruments and ways of accomplishment of the content analysis are described, pointing the course in that the decisions went being taken in relation to the handling techniques with the documents: from the organization and classification of the material until the elaboration of the categories of analysis. In this study it was adopted a perspective of the historiography that tried to overcome the dichotomy between the approaches internal and external of the history of sciences, propitiating to understand the partner-historical ambit in that was constituted the cited scientific production. 
Estudos baseados em documentos como material primordial, sejam revisões bibliográficas, sejam pesquisas historiográficas, extraem deles toda a análise, organizando-os e interpretando-os segundo os objetivos da investigação proposta. É, pois, o tratamento metodológico de documentos que destacarei neste trabalho, tendo como pano de fundo meu prórpio percurso de pesquisa.

$\bigcirc$ material pesquisado sobre essa metodologia raramente apresentava o percurso do pesquisador, desde o momento em que estabelece sua meta de pesquisa até as conclusões apresentadas mediante a análise. Como bem denomina Mitsuko Antunes, trata-se de um processo de "garimpagem"'; se as categorias de análise dependem dos documentos, eles precisam ser encontrados, "extraídos" das prateleiras, receber um tratamento que, orientado pelo problema proposto pela pesquisa, estabeleça a montagem das peças, como num quebra-cabeça. Esse artigo tem a finalidade de apresentar meu próprio processo de garimpagem, esperando que seja útil a outros pesquisadores que se interessam pela análise de documentos.

A pesquisa intitulada Um estudo de caso na relação entre psicologia e educação: o Programa Alfa (Pimentel, 1997) objetivou investigar os intercâmbios da psicologia com a formulação de propostas educacionais, tendo o Programa $\mathrm{Alfa}^{2}$ como exemplo dessa inter-relação.

À luz de uma perspectiva histórica, a análise documental correspondeu à atuação e produção da coordenadora do Alfa, Ana Maria Poppovic, abrangendo o período de 1953 a 1983. Para desenvolver o trabalho analítico, foi objeto central de interesse a produção escrita pela educadora, bem como referências bibliográficas sobre o momento sócio-histórico que influenciou a elaboração daquele programa, no que diz respeito à psicologia e suas relações com a educação.

Inicialmente, essa delimitação não existia, ela já é resultante do que os documentos apontavam sobre o contexto em que se inseria o Alfa. Foi preciso, portanto, retroceder ao período em que se encontravam as suas origens para engendrálo nos primeiros estudos com foco educacional realizados por Poppovic.

No início da pesquisa, eu conhecia o programa apenas por um artigo de Ana Maria Poppovic ( 1982). Na verdade, o artigo havia despertado meu interesse

I. Termo utilizado pela pesquisadora em aulas da disciplina História da Psicologia no Brasil, em curso de Pós-Graduação em Psicologia da Educação da PUC/SP.

2. Proposta de alfabetização, de âmbito nacional, executada entre 1977 e 1985. 
unicamente pelo fato de que nele havia referência sobre a teoria de Lev S. Vigotski, autor que, até então, era o centro de meus estudos. E foi exatamente por isso que considerei necessário saber o que significava aquela proposta dirigida à alfabetização, colocada em prática e, acima de tudo, desenvolvida teoricamente à luz de postulados psicológicos, dentre os quais a abordagem vigotskiana se sobressaía como um de seus quatro princípios. A surpresa que fez redimensionar meu projeto de pesquisa explica-se pelo fato de que a primeira publicação brasileira de uma obra de Vigotski data de 1984. Então, como esse autor pôde constituir-se numa das principais referências para uma experiência de ensino, executada a partir de meados da década de 1970, quando não tinha o espaço de divulgação que teve posteriormente? Melhor dizendo, intrigou-me o processo pelo qual a relação entre teoria e prática se materializa.

Ao mesmo tempo em que o problema da pesquisa tornou-se mais definido, iniciei as minhas visitas à biblioteca da Pontifícia Universidade Católica de São Paulo - PUC-SP - com o propósito de encontrar o que ali se dispunha sobre a coordenadora daquele audacioso projeto de alfabetização. Aliás, o meu conhecimento sobre a pesquisadora se restringia, até então, a duas informações: ela havia lecionado na PUC-SP, na época, Faculdade São Bento, e era presumível que sua carreira acadêmica tenha sido notável, pois seu nome é atribuído à Clínica-Escola da Faculdade de Psicologia desta universidade e a um concurso de melhor trabalho de conclusão de curso, promovido pela Fundação Aniela e Tadeuz Ginsberg FATG -, também sediada na PUC-SP ${ }^{3}$.

Portanto, era bastante possível que o acervo da biblioteca fosse uma fonte rica de documentos. Nela, obtive acesso à tese de Poppovic, além de grande parte de seus artigos, publicados nos periódicos Revista de Psicologia Normal e Patológica-RPNP - ${ }^{4}$ e Cadernos de Pesquisa.

É importante salientar que esse último periódico é uma publicação da Fundação Carlos Chagas - FCC -, o centro de pesquisa onde Poppovic elaborou o Alfa. Portanto, era apenas uma questão de tempo para que as minhas visitas à Biblioteca desse instituto se tornassem tão constantes quanto às da PUC-SP. Foi na fundação que vi pela primeira vez todo o material do Alfa, além de outras publica-

3. No decorrer da pesquisa, soube também que "Ana Maria Poppovic" é o nome da biblioteca da Fundação Carlos Chagas e de uma praça próxima ao local em que faleceu, na capital paulista.

4. Publicação editada pelo Instituto de Psicologia da PUC-SP entre 1955 e 1973. 
ções. Um dos documentos mais valiosos que encontrei foi uma cópia de um curriculum vitae - um verdadeiro achado, pois orientou o levantamento bibliográfico e trouxe outra fonte de informações importantíssima: as atividades desenvolvidas por aquela pesquisadora até o ano de 1982, um ano antes de seu falecimento. Por fim, lá estavam arquivados vários números do Jornal Alfa, algo que desconhecia até o dia em que pedi auxílio à bibliotecária para encontrar uma publicação em que pudesse "ver" Poppovic, ou seja, encontrar uma fotografia, original ou publicada. Isso pode ser tomado apenas como curiosidade, mas foi exatamente essa curiosidade que me levou à coletânea desses jornais, material de grande relevância para compreender fatos que, mais tarde, determinariam a realização de um outro programa importante dentre as atividades desenvolvidas por Poppovic, agora voltado aos educadores, o Pensamento e Linguagem ${ }^{5}$.

A seguir, apresento o processo de pesquisa, mediado com a explicitação de algumas das informações que considero mais importantes para se compreender a metodologia empregada, de modo que faça sentido para o leitor a divisão de caráter didático em que organizo as decisões que foram necessárias no decorrer da investigação.

Numa primeira etapa, meu objetivo era encontrar fontes e, nelas, os documentos necessários para a pesquisa. Não havia preocupação com a análise propriamente dita, que seria núcleo do trabalho subseqüente, com a organização do material. Nesse momento, importava tão-somente a obtenção de informações advindas de publicações, anais de congressos, vídeos, além de referências sobre a obra dessa pesquisadora. No entanto, as fontes sempre eram anotadas e a documentação arquivada, primeiramente, segundo o local onde foi encontrada.

Também passou a ser incluída, como fonte de informações, a Fundação Aniela e Tadeuz Ginsberg. Nessa fundação, obtive informações sobre as atividades de Poppovic por meio de consulta a: livro de atas das reuniões do Departamento de Psicologia da Faculdade de Filosofia, Ciências e Letras de São Bento - FFCLSB -; livro de atas do Curso Experimental de Psicologia dessa faculdade, realizado no segundo semestre de 1968; vídeo em homenagem aos dez anos do falecimento de Ana Poppovic, gravado pela Clínica Psicológica da PUC-SP, e um depoimento de uma ex-docente do Instituto de Psicologia da PUC - IPPUC-SP -, gravado em fita cassete. Mediante relatórios de pesquisas da FATG, sobre a história do IPPUC-SP (1950- 1973), foi possível encontrar outras informações relevantes para o estudo.

5. Programa de aperfeiçoamento para professores primários, desenvolvido em caráter experimental em São Paulo e em Pernambuco, em 1980. 
É importante comentar que optei por não priorizar determinado tipo documental, reunindo tudo o que estivesse associado à produção da autora. Desse modo, o conjunto de documentos, além dos livros e artigos, foi composto por:

a. outros escritos: manuais, anais, atas de reuniões, publicações resultantes de seminários e palestras realizadas, relatórios, projetos e curriculum vitae;

b. materiais não impressos que subsidiassem a leitura da obra da autora: vídeos, fita cassete e fotografias;

c. apreciações críticas sobre a produção de Poppovic: textos com referências biográficas e publicações que traziam análises sobre o Programa Alfa e outras propostas de alfabetização.

Às informações contidas em curriculum vitae foram acrescidas outras obtidas em referências bibliográficas e notas de rodapé de artigos e livros. Aliás, em diversas ocasiões, foram encontradas informações importantes, justamente em comentários escritos em notas de rodapé, tais como a identificação de outras atividades exercidas por Poppovic e o acesso aos fascículos e fitas de vídeo do projeto Pensamento e Linguagem5.

Paralelamente, necessitando obter subsídios para a análise referente às contribuições da autora, foram consultados diversos tipos de publicações que tratavam de: a) história da psicologia e de seus vínculos com a educação no Brasil; b) análises sobre a relação teoria-prática; c) reflexões e questionamentos acerca da relação psicologia-educação. Além disso, a consulta à bibliografia tanto contemporânea à obra de Poppovic quanto da atualidade, relativa aos principais temas abordados em suas obras, contribuiu para melhor compreender o contexto em que a autora produziu, evitando distorções na análise.

\section{ORGANIZAÇÃO DO MATERIAL COLETADO}

Nesta fase do estudo, foi realizada uma primeira organização do material, quando tornou-se indispensável olhar para o conjunto de documentos de forma analítica, buscando averiguar como poderia proceder para torná-lo inteligível, de acordo com o objetivo de investigar os vínculos da psicologia com a prática em educação.

Todos os documentos eram arquivados em pastas ao mesmo tempo em que dava prosseguimento à coleta. $\bigcirc$ critério estabelecido para tal organização foi a fonte documental. As leituras e fichamentos tiveram papel central nessa fase. Para 
cada documento foi criada uma ficha de leitura contendo resumo, referência bibliográfica da publicação, além de algumas transcrições de trechos que poderiam ser utilizados posteriormente.

Organizar o material significa processar a leitura segundo critérios da análise de conteúdo, comportando algumas técnicas, tais como fichamento, levantamento quantitativo e qualitativo de termos e assuntos recorrentes, criação de códigos para facilitar o controle e manuseio. Dessas ações, no estudo realizado, resultaram dois quadros. $\bigcirc$ primeiro deles sintetizou a classificação realizada sobre todo o material obtido, seguindo a cronologia das publicações. $\bigcirc$ segundo, conteve as temáticas que mais insistentemente ocuparam o universo de pesquisa de Poppovic. De certa forma, esses quadros se constituíram num banco de dados de informações, cuja vantagem consistiu em poder relacioná-las, sem perder de vista a contextualização de toda a obra. Mais adiante, ambos os quadros são apresentados.

Tal organização permitiu identificar três circunstâncias distintas da produção de Ana Poppovic: a) o trabalho desenvolvido no IPPUC-SP, com a utilização principalmente das RPNPs; b) sua atuação na FCC, por meio dos artigos publicados nos Cadernos de Pesquisa e c) o período correspondente à elaboração e ao desenvolvimento do Alfa - descritos no próprio material do programa, como no Jornal Alfa, nas Cartas à Professora e em artigos - até a criação do Pensamento e Linguagem.

Conforme demonstrado no Quadro I, outras pastas serviram para materiais de consulta, tal como os referentes à história da psicologia. Com exceção do restante da obra de Poppovic, dois de seus textos foram arquivados numa dessas pastas, na de "leituras 2", pelo fato de conterem dados autobiográficos, ainda que não tenham sido produzidos para esse fim, com a ressalva de que apresentam posições dela sobre assuntos a serem analisados como, por exemplo, a questão do fracasso escolar. 


\section{QUADRO I \\ PRIMEIRAETAPA DE ORGANIZAÇÃO DO MATERIAL}

\begin{tabular}{|c|c|c|}
\hline Título & Caracterização do material & Caracterização do conteúdo das fichas \\
\hline RPNP & $\begin{array}{l}\text { artigos publicados na Revista de } \\
\text { Psicologia Normal e Patológica. }\end{array}$ & $\begin{array}{l}\text { referência completa do periódico, número } \\
\text { de páginas, local em que foi encontrado e } \\
\text { respectiva identificação catalográfica, } \\
\text { resumo e citações de alguns trechos, } \\
\text { código atribuído. }\end{array}$ \\
\hline$\overline{\mathrm{CP}}$ & $\begin{array}{l}\text { artigos publicados nos Cadernos de } \\
\text { Pesquisa. }\end{array}$ & $\begin{array}{l}\text { mesma caracterização das fichas das } \\
\text { RPNPs. }\end{array}$ \\
\hline ALFA & $\begin{array}{l}\text { Cartas à Professora de } \\
\text { Alfa } 1,2 \text { e } 3 .\end{array}$ & $\begin{array}{l}\text { mesma caracterização das fichas das } \\
\text { RPNPs, contendo, ainda, comentários } \\
\text { sobre o conteúdo das Cartas. }\end{array}$ \\
\hline $\begin{array}{l}\text { Material } \\
\text { do Alfa }\end{array}$ & material didático do Programa Alfa. & $\begin{array}{l}\text { listagem, com comentários, do conteúdo } \\
\text { dos materiais impressos que compõem o } \\
\text { Alfa. }\end{array}$ \\
\hline Outros & $\begin{array}{l}\text { artigos em outros periódicos, } \\
\text { seminários, xerox (parciais) de } \\
\text { livros e do Relatório do } \\
\text { Pensamento e Linguagem. }\end{array}$ & $\begin{array}{l}\text { mesma caracterização das fichas de artigos } \\
\text { de RPNP, incluindo-se tipo documental } \\
\text { (ex.: periódico, seminário) e respectivos } \\
\text { comentários. }\end{array}$ \\
\hline $\mathrm{CV}$ & $\begin{array}{l}\text { Curriculum vitae - de } 1970 \text { e de } \\
1982 .\end{array}$ & $\begin{array}{l}\text { fichas constituídas por esquema contendo } \\
\text { as informações dos documentos. }\end{array}$ \\
\hline Fichas RB & $\begin{array}{l}\text { fichas de referências bibliográficas: } \\
\text { pesquisas e autores que poderiam } \\
\text { contribuir para análise da obra de } \\
\text { Poppovic ou para a história da } \\
\text { psicologia e da educação. }\end{array}$ & $\begin{array}{l}\text { foram criados } 2 \text { tipos de fichas: a) um, } \\
\text { apresentando as referências específicas de } \\
\text { temas relacionados à obra de Poppovic } \\
\text { (ex.: carência cultural) e b) outro, para } \\
\text { bibliografia relativa à psicologia e } \\
\text { educação. }\end{array}$ \\
\hline História & $\begin{array}{l}\text { textos cuja temática se refere à } \\
\text { história da educação e/ou da } \\
\text { psicologia, pesquisas sobre a } \\
\text { história do IPPUC-SP. }\end{array}$ & $\begin{array}{l}\text { além da referência completa de cada } \\
\text { documento, foram listadas "palavras- } \\
\text { chave" (com o número da página } \\
\text { correspondente) e citados trechos que } \\
\text { poderiam ser utilizados posteriormente. }\end{array}$ \\
\hline Leitura 1 & $\begin{array}{l}\text { textos acerca da relação entre teoria } \\
\text { e prática e textos sobre metodologia } \\
\text { de pesquisa. }\end{array}$ & $\begin{array}{l}\text { além de referência completa, resumo e } \\
\text { algumas citações, em algumas fichas } \\
\text { foram anotadas reflexões sobre os } \\
\text { assuntos tratados. }\end{array}$ \\
\hline Leitura 2 & $\begin{array}{l}\text { textos abordando a relação entre } \\
\text { psicologia e educação; apreciações } \\
\text { críticas da obra de Poppovic ou } \\
\text { sobre o Alfa, incluídos textos da } \\
\text { autora de caráter autobiográfico. }\end{array}$ & $\begin{array}{l}\text { na ficha de cada texto foram feitas } \\
\text { anotações e comentários sobre os temas } \\
\text { em questão, além do registro da referência } \\
\text { completa. }\end{array}$ \\
\hline
\end{tabular}


TABELA 2

SEGUNDA ETAPA DE ORGANIZAÇÃO DO MATERIAL

\begin{tabular}{|c|c|}
\hline Título da Pasta & Descrição do material de cada pasta \\
\hline $\begin{array}{l}\text { Estudos de casos } \\
\text { clínicos }\end{array}$ & $\begin{array}{l}\text { publicações tratando do trabalho clínico, em que se discute: a) etapas do } \\
\text { atendimento terapêutico desde o diagnóstico, b) considerações teóricas } \\
\text { acerca de procedimentos e técnicas empregadas no atendimento clínico } \\
\text { e c) especificidades do tratamento psicoterapêutico. }\end{array}$ \\
\hline $\begin{array}{l}\text { Dislexia, disfunções } \\
\text { psiconeurológicas - } \\
\text { alfabetização }\end{array}$ & $\begin{array}{l}\text { escritos abordando teórica e metodologicamente quadros denominados } \\
\text { síndromes psiconeurológicas e seus efeitos na aprendizagem. A } \\
\text { psicologia da personalidade e do desenvolvimento fundamenta as } \\
\text { posições relativas às dificuldades de caráter psiconeurológico para se } \\
\text { estabelecer conclusões quanto ao tratamento terapêutico e pedagógico } \\
\text { de tais disfunções. }\end{array}$ \\
\hline $\begin{array}{l}\text { TMP, maturidade } \\
\text { para aprendizagem e } \\
\text { prontidão para } \\
\text { alfabetização }\end{array}$ & $\begin{array}{l}\text { textos descrevendo os estudos de validação do Teste Metropolitano de } \\
\text { Prontidão, além do próprio manual do teste criado para identificar o } \\
\text { grau de maturidade psicológica da criança necessário à aprendizagem. } \\
\text { São abordados os aspectos fundamentais do desenvolvimento de } \\
\text { funções psicológicas específicas envolvidas na prontidão para a } \\
\text { alfabetização. }\end{array}$ \\
\hline $\begin{array}{l}\text { Relações entre } \\
\text { psicologia e } \\
\text { alfabetização }\end{array}$ & $\begin{array}{l}\text { publicações relativas à interdisciplinaridade envolvida no processo de } \\
\text { aprendizagem, especialmente no início da escolarização. Conceitos da } \\
\text { psicologia do desenvolvimento constituem o eixo das formulações } \\
\text { acerca dos aspectos que influenciam negativamente o desenvolvimento } \\
\text { cognitivo e, portanto, a maturidade necessária à prontidão para a } \\
\text { alfabetização. }\end{array}$ \\
\hline $\begin{array}{l}\text { Marginalização } \\
\text { cultural }\end{array}$ & $\begin{array}{l}\text { publicações que explicitamente tratam do tema, apresentando: métodos } \\
\text { de estudo, conceituação, perspectivas teóricas envolvidas, } \\
\text { determinação dos fatores ambientais de marginalização, efeitos na } \\
\text { realização escolar. O desenvolvimento de pesquisas empíricas e a } \\
\text { formulação de instrumentos de medição concorrem para a apresentação } \\
\text { de sugestões e propostas de planejamento pedagógico, didático e } \\
\text { curricular que possam viabilizar a reversão do processo de } \\
\text { marginalização que se intensifica na escola. }\end{array}$ \\
\hline $\begin{array}{l}\text { Programa } \\
\text { Alfa }\end{array}$ & $\begin{array}{l}\text { material pedagógico deste programa, artigos que o descrevem técnica e } \\
\text { teoricamente, exemplares do Jornal Alfa e apreciações críticas de } \\
\text { outros autores acerca do Alfa ou que debatem assuntos correlatos. }\end{array}$ \\
\hline $\begin{array}{l}\text { Pensamento e } \\
\text { linguagem }\end{array}$ & $\begin{array}{l}\text { transcrição resumida das } 15 \text { aulas apresentadas em fitas de vídeo, } \\
\text { fotocópia parcial do relatório de análise do projeto e dos fascículos em } \\
\text { que são apresentadas as estratégias desse programa de treinamento em } \\
\text { serviço e diversos exercícios para serem realizados pelas professoras. }\end{array}$ \\
\hline $\begin{array}{l}\text { Postura política } \\
\text { diante de assuntos } \\
\text { vários, articulada } \\
\text { com o binômio } \\
\text { teoria-prática }\end{array}$ & $\begin{array}{l}\text { escritos que, ao abordarem temáticas diversas, expressam posições de } \\
\text { ordem política e teórico-metodológica da autora. Em tais publicações, } \\
\text { evidencia-se a defesa da idéia de que ao desenvolvimento científico } \\
\text { estejam imbricadas aplicações que atendam a necessidades práticas e } \\
\text { imediatas. Com este fim são debatidos: a produção de conhecimento na } \\
\text { atuação em clínica, os objetivos da pesquisa em psicologia, problemas } \\
\text { e perspectivas quanto ao planejamento curricular do sistema } \\
\text { educacional, temáticas inseridas no problema do fracasso escolar, a } \\
\text { urgência de se pensar e elaborar o planejamento didático e curricular } \\
\text { para atender o nível pré-escolar de ensino. }\end{array}$ \\
\hline
\end{tabular}


A segunda organização, mediante releitura da obra de Poppovic, seguiu o critério de assunto, ou seja, aspectos temáticos e conceituais das publicações. Com isso, tornou-se mais importante manter juntos determinados documentos que tratavam explicitamente do mesmo assunto, independentemente de correlação cronológica.

Nesse momento, foi fundamental analisar os textos e encontrar a linha mestra que os conduzia, relacionar um ao outro, reconhecer a gênese dos principais trabalhos de Poppovic e seus métodos de pesquisa e, sobretudo, identificar os eixos teóricos com os quais ela mais se identificava.

Como se observa, o próprio material dirigiu o estabelecimento dos temas que viriam a compor as categorias de análise, diferentemente da organização antecedente, na qual a fonte e data de publicação orientaram o trabalho, para que se pudesse conhecer o que havia sido feito por Poppovic antes, durante e depois do Programa Alfa.

\section{PROCEDIMENTOS DA ANÁLISE DOCUMENTAL}

Para desenvolver a análise, além de contar com os arquivos organizando toda a documentação e com as fichas de leitura, foram construídos quadros de autores e de termos-chave, aos quais se acrescentaram observações ou comentários sobre possíveis relações com as questões da pesquisa.

O objetivo com tais procedimentos foi mapear a trajetória de Poppovic e, principalmente, conhecer os caminhos percorridos para a elaboração do Programa Alfa, bem como a produção decorrente dele, resultante de questões suscitadas em meio à sua execução.

\section{Quadros de autores}

No decorrer da elaboração das fichas de leitura, diversas questões foram levantadas, como, por exemplo, em que estaria se pautando a autora para utilizar, a partir de 1972, o termo "marginalização cultural", quando se constata em obras de anos anteriores a denominação "marginalidade"? Em que fundamentava a definição de funções psicológicas e operações mentais específicas para a aprendizagem, ambas objeto central da definição do currículo para o Programa Alfa?

Tornou-se premente contextualizar com maior adequação os conceitos utilizados por Poppovic ao longo de sua obra, considerando valiosa a identificação das referências teóricas nas quais ela se pautava para tratar de determinado assunto. Os quadros de autores tiveram essa finalidade, a de auxiliar na análise tanto 
quantitativa como qualitativa em relação a autores citados e/ou presentes em referências bibliográficas.

Do ponto de vista quantitativo foi averiguada a freqüência com que os diversos autores eram apontados nas formulações conceituais de Poppovic e, dessa forma, observam-se alterações de referenciais ao longo de sua trajetória. Qualitativamente, foi possível identificar as principais influências teóricas que subsidiaram sua produção, considerando: o uso das abordagens científicas em seus postulados teórico-metodológicos; relação de teóricos com os quais ela estabelecera um diálogo consubstancial, nos diferentes momentos de sua obra; identificação de diferentes períodos de produção no decorrer dos 30 anos de sua atividade profissional, por exemplo, verificando reformulações conceituais ou surgimento de novos conceitos fundamentados em autores não citados anteriormente.

Sobre cada publicação, o quadro criado continha as seguintes informações: título, data, número de página inicial e final, no cabeçalho. Em colunas, foram apontados: I) autor citado; 2) localização no texto; 3) contexto da citação; 4) a própria citação; 5) observações; 6) referência bibliográfica e 7) número da página da citação.

Em alguns casos, foi incluída a citação da própria Poppovic referindo-se a um autor, seja apresentando suas idéias, seja expressando opinião sobre ele, sem fazê-lo sob a forma de citação propriamente dita.

A coluna designada para especificar o contexto da citação informava sobre o assunto a que, particularmente, apresentavam-se as referências a um ou mais teóricos. No espaço para observações eram inseridas informações adicionais sobre o assunto, considerações complementares da autora e alguns comentários meus de caráter interpretativo.

Para ilustrar, tomarei como exemplo um dos apontamentos de Poppovic, tratando da importância do sistema lingüístico no processo de aprendizagem. Sobre isso, há referências à obra de Alexandre R. Luria (1966, 197I), autor em que ela se baseia para afirmar que "a fala, a leitura e a escrita não podem ser consideradas funções autônomas e isoladas, mas sim manifestações de um mesmo sistema, que é o sistema funcional da linguagem" (Poppovic, 1968, p.29). Dessa forma, a linguagem é reguladora do comportamento, dando oportunidade para que a criança adquira

...novas formas de atenção, memória, imaginação, pensamento e ação. Suas pesquisas [do autor] levam-no a afirmar que a aquisição de um sistema funcional da linguagem produz não somente um aperfeiçoamento na comunicação, mas também importantes desenvolvimentos na estrutura das operações mentais. (Poppovic, 1982, p.33) 


\section{Quadros de termos-chave}

Estruturados de modo semelhante aos quadros de autores, os de termoschave tiveram o propósito de instrumentalizar a análise dos conceitos fundamentais apresentados nos documentos. Nessa etapa, foram identificados os núcleos conceituais que atendiam à caracterização da obra de Poppovic.

Num estágio inicial, foram grifadas, nos textos, palavras e frases que sintetizavam um conceito, apontavam uma proposta, definiam uma concepção ou simplesmente expressavam uma idéia que parecia ter relevância no bojo do assunto em discussão.

A ordem de leitura seguiu a organização do material, como figura no Quadro 2, pelo conjunto de textos que representavam um determinado tema previamente esboçado, por exemplo, as publicações referentes à "marginalização cultural". No decorrer do processo de releitura, alguns elementos foram destacados, representando uma classe conceitual. As fichas de leitura, quadros de autores e anotações feitas nos próprios documentos eram retomados para orientar o levantamento dos aspectos centrais envolvidos com o tema de cada conjunto de textos.

A seleção dos termos-chave foi definida em razão de dois fatores: I) freqüência de determinado segmento, em geral constituído por um conjunto de algumas palavras representando uma idéia e 2) associado ao primeiro, o segundo fator considerava os contextos em que tais segmentos se apresentavam.

terceiro princípio norteador do Programa Alfa, um dos termos-chave levantados, servirá, aqui, como exemplo:

Termo-chave: Linguagem/Princípio - "estimular por todos os meios o enriquecimento da linguagem” (Poppovic et al., 1977, p.28). No contexto de definição do currículo do Alfa, significava criar espaço para a ocorrência da comunicação livre, entendida como fundamental para o desenvolvimento da capacidade de raciocinar, sendo a linguagem um instrumento vital para: a) adquirir novas aprendizagens; 2) organizar os processos mentais; 3) desenvolver a cognição e 4) planejar atitudes e comportamentos.

\section{Tratamento dos dados}

Empregando técnicas usuais da análise de conteúdo para decifrar, em cada texto, o núcleo emergente que servisse ao propósito da pesquisa, essa etapa consistiu num processo de codificação, interpretação e de inferências sobre as informações contidas nas publicações, desvelando seu conteúdo manifesto e latente. 
A partir da correlação entre os quadros de termos-chave e os de autores foi composto, inicialmente, um número elevado de itens, impondo a necessidade de planejar um meio de classificá-los a fim de vislumbrar uma síntese que representasse o conjunto da obra de Poppovic, identificando, assim, as unidades de análise. Tais unidades se constituíram em núcleos de significado que sistematizavam um conjunto de assuntos, mediante as inferências realizadas sobre o conteúdo a que se referiam os diversos termos-chave.

Assim, foram definidas as seguintes unidades de análise:

I. disfunções psiconeurológicas;

2. determinantes do fracasso escolar;

3. fatores ambientais de marginalização cultural;

4. prontidão para a alfabetização;

5. Teste Metropolitano de Prontidão;

6. educação compensatória;

7. concepção de pré-escola não-compensatória;

8. planejamento curricular;

9. princípios teóricos do Programa Alfa;

10. características didáticas e metodológicas do Alfa;

I I. funções psiconeurológicas para alfabetização;

12. operações cognitivas para alfabetização;

13. autoconceito positivo;

14. desenvolvimento do pensamento e processo de ensino-aprendizagem;

15. papel do professor, da escola e da família no processo de aprendizagem;

16. estrutura e didática do Pensamento e Linguagem;

17. formação e treinamento do professor;

18. políticas educacionais.

trabalho realizado com os termos e, em seguida, com as unidades de análise foi importante para a compreensão da obra de Poppovic, do ponto de vista teórico. No entanto, para estabelecer relações com a prática educacional, foi preciso definir indicadores, ou seja, a que tipo de informações estaria associado determinado conjunto de unidades de análise. Primeiramente, procurei averiguar se as unidades de análise correspondiam, de fato, a uma interpretação que garantisse 
homogeneidade e coerência ao conjunto mais amplo de termos-chave. Ao término de exaustiva revisão da lista de unidades, as mesmas foram distribuídas de acordo com o conteúdo abordado (manifesto) e o significado (latente) consoante ao que vem a ser inter-relações de teorias (psicológicas) com práticas (pedagógicas). Com isso, foram definidos os seguintes indicadores: caracterização de fenômenos pesquisados, bases teóricas, conceitos, propostas didático-metodológicas, concepções políticas e, por fim, metodologia de pesquisa.

O último indicador, em verdade, abordou o estilo de trabalho empreendido por Poppovic ao investigar um tema de pesquisa. Foi incluído por estar intimamente vinculado a procedimentos que refletiam a maneira como ela tratava o binômio teoria-prática, por meio de características presentes nos relatos de suas investigações.

Por sua vez, os indicadores passaram por nova análise a fim de verificar a possibilidade de elaborar novos agrupamentos, realizar alterações, detectar aspectos ainda não incluídos e verificar novas relações. Só então foram definidos como categorias que, de acordo com a temática, delinearam os assuntos subjacentes ao estudo. Conforme apontam Lüdke e André, as categorias devem explicitar os propósitos da pesquisa e, ao mesmo tempo, ser internamente homogêneas, externamente heterogêneas, coerentes e plausíveis (1986, p. 43).

É válido ressaltar também que, dada a preocupação em garantir a contextualização sócio-histórica, mantive inalterados aspectos semânticos e nomenclaturas. No entanto, sempre que necessário, foram consultados autores e análises críticas contemporâneas como também obras da época, abrangendo assuntos específicos, com o intuito de melhor apreender o(s) significado(s) atribuído(s) a um termo, concepção ou idéia proposta. Sem dúvida, por exemplo, a consulta a obras tratando de pré-escola, da época de 70 e da atualidade, foi valiosa para dar conta de compreender a sua interveniência no discurso da autora e, por conseguinte, em sua teorização e prática sobre a alfabetização - à qual estava associado um compromisso político com aquele nível de ensino, na época, despojado de dispositivos legais e de ações governamentais que the conferissem caráter eminentemente educativo, precedente ao processo de alfabetização propriamente dito.

\section{A PESQUISA COMO RECONSTITUIÇÃO DA MEMÓRIA DA CIÊNCIA}

Dependendo do objetivo da pesquisa, a análise de documentos pode se caracterizar como instrumento complementar ou ser o principal meio de 
concretização do estudo, como é o caso da investigação historiográfica, sobre a qual apresento a seguir alguns comentários.

Embora alguns personagens, instituições e acontecimentos não pertençam ao cenário atual, isto não significa que estejam confinados ao esquecimento. Ao contrário, eles estão presentes de alguma forma em cada um de nós, em nossa atuação e em nossa produção de conhecimento, pois estamos envolvidos e partimos exatamente do que anteriormente foi elaborado.

Investigar o fazer e o saber de personagens que produziram o conhecimento psicológico é desenvolver um trabalho de reconstituição da memória desta área científica que, muitas vezes, vive e revive "crises" acerca dos paradigmas que emergem da própria complexidade de seu objeto de estudo e como conseqüência do pouco tempo de sua autonomia como campo científico. Mas, conforme argumenta Pessotti:

...a psicologia está se mostrando adulta ainda que pela simples disposição de examinar-se. [...] Não apenas no plano institucional, mas também no campo acadêmico, a psicologia do Brasil está pronta para analisar-se e, pois, madura, não só para retratar o seu atual estágio mas para pesquisar as raízes de seus aspectos atuais, o curso de sua evolução. (1988, p. 17-8)

De fato, a produção de idéias e saberes científicos tem um caráter eminentemente social, pois estes

...são representações da vida do ser humano, num dado momento de sua história, [...] o conhecimento não é fruto da atividade isolada do ser humano, ao contrário, tem um caráter coletivo, mesmo quando formulado ou difundido por um único homem. O homem vive em sociedade e é a partir desta vida que as idéias são criadas. A transmissão destas idéias, oralmente ou por escrito, permite acumular conhecimentos. (Savioli et al., 1986, p.2)

No processo de articulação do presente com o passado, o pesquisador volta-se às suas raízes, ativa ou reativa a memória, distanciando-se assim de uma possível fragmentação quando procura, na investigação, o elo entre esses dois tempos históricos da atividade humana, para além de análises "presentistas" que o levariam apenas a ratificar o passado e glorificar o presente. A pesquisa historiográfica constitui-se em evidências coordenadas e interpretadas, exigindo do pesquisador o trabalho de suplantar sua própria contemporaneidade sem deixar-se cair, entretanto, num historicismo que se traduziria em anacronismo, numa interpretação errônea, distorcida do passado. 
A investigação confere um valor histórico ao documento à medida que o pesquisador é capaz de superar os limites inerentes ao próprio material com que trabalha e, ao mesmo tempo, reconhece serem sua postura e experiência de vida compostas por uma bagagem que é histórica, "tornando-o um objeto, isto é, o historiador é também fruto de seu tempo" (Vieira et al., 1989, p.30). Sobre tais aspectos, comenta Marina Massimi:

O objeto da pesquisa histórica é constituído por documentos que transmitem ao historiador a realidade do passado de uma forma parcial, proporcionando um conhecimento que é "mutilado", segundo Paul Veyne. De fato, o documento representa já uma interpretação de fatos reais elaborada por seu autor e, portanto, não deve ser encarado como uma descrição objetiva e neutra dos fatos. Por outro lado, o valor heurístico e a significação do documento dependem também da acuidade da leitura e do esforço interpretativo do historiador. Este sabe extrair de uma fonte de informações algum conhecimento útil para a compreensão de um aspecto da história humana, sob o ângulo que corresponde ao seu objeto de interesse. É esse interesse que move e orienta continuamente o pesquisador na busca de documentos. (1984, p.21-2)

A análise da obra de Poppovic permitiu compreender melhor o processo de intersecção de conhecimentos psicológicos (acerca de desdobramentos psíquicos intrínsecos ao desenvolvimento humano e aos mecanismos de aprendizagem) com a ação pedagógica, ou seja, como se tornaram alicerce para a educação e, inversamente, foram construídos mediante o intercâmbio com as demandas da realidade educativa.

Cabe, ainda, ponderar sobre as possibilidades que a pesquisa biográfica oferece para a superação da dicotomia entre as visões internalista e externalista ${ }^{6}$ nos estudos historiográficos. No caso do estudo sobre a obra de Poppovic foi possível reaver tanto suas próprias idéias como as da comunidade científica no tempo e contexto em que atuou.

Um determinado contexto histórico e sociocultural é necessariamente o limite e a base em que todo pesquisador transforma a realidade fatual em ideal, isto é, torna-a objeto de investigação científica a partir dos conhecimentos e instru-

6. Os historiadores "externalistas" propõem uma explicação do desenvolvimento científico segundo "causas infraestruturais de ordem econômica e social" (Massimi, I995, p.7), subjacentes ao progresso científico. Na perspectiva "internalista", a história das ciências deve pautar-se na própria dinâmica de cada ciência, "independente das condições externas (idem, ibidem). 
mentos de que dispõe. Na história da psicologia no Brasil, Poppovic retrata os princípios em que se desenvolveu a pesquisa no passado recente, particularmente no âmbito da aprendizagem no início da escolarização.

No entanto, o que torna sua obra exemplo expressivamente importante decorre de sua ardorosa e entusiástica busca para tornar exeqüível a teoria, superando o caráter ideal do conhecimento teórico, cuidando para não submeter os fenômenos e sua interação com a ação humana a padrões explicativos, imersos numa perspectiva teórica contemplativa. Ao desenvolver projetos de intervenção, tal como foi o Programa Alfa, pôde transcender a dicotomia teoria e prática bastante presente no campo do conhecimento psicológico dirigido à ação educacional.

\section{REFERÊNCIAS BIBLIOGRÁFICAS}

BROZEK, J.; MASSIMI, M. Historiografía da psicologia moderna: versão brasileira. São Paulo: Unimarco; Loyola, 1998.

LÜDKE, M., ANDRÉ, M. E. D. A. Pesquisa em educação: abordagens qualitativas. São Paulo: EPU, 1986.

LURIA, A. S. Higher cortical functions in man. New York: Basic Books, 1966.

Speech and the development of mental processes in the child. Hazmondsworth: Penguim Books, 1971.

MASSIMI, M. História das idéias psicológicas no Brasil, em obras do período colonial. São Paulo, 1984. Dissert. (mestr.) Psicologia, USP.

A Dimensão histórica da história das ciências e de seu objeto. Ribeirão Preto, 1995. mimeo. [Documento elaborado para a 25a Reunião Anual da Sociedade Brasileira de Psicologia].

PESSOTTI, I. Notas para uma história da Psicologia brasileira. In: CONSELHO FEDERAL DE PSICOLOGIA. Quem é o psicólogo brasileiro? São Paulo: Edicon, 1988. p. $17-31$.

PIMENTEL, A. Um Estudo de caso na relação entre psicologia e educação: o Programa Alfa. São Paulo, 1997. Dissert. (mestr.) Psicologia da Educação, PUC.

POPPOVIC, A. M. Alfabetização: disfunções psiconeurológicas. São Paulo: Vetor, 1968.

Bases teóricas do Programa Alfa. Cadernos de Pesquisa, São Paulo, n. 43, p.31-6, nov. 1982.

POPPOVIC, A. M. et al. Programa Alfa Um: cartas à professora de Alfa Um. São Paulo: Editora Abril; Fundação Carlos Chagas, 1977. 
SAVIOLI, M. et al. Considerações sobre a elaboração e a comunicação do conhecimento científico. São Paulo, 1986. mimeo. [Material elaborado para curso de Especialistas em Homeopatia].

VYGOTSKY, L.S. Pensamento e linguagem. São Paulo: Martins Fontes, 1984.

VIEIRA, M. P. A. et al. A Pesquisa em história. São Paulo: Ática, 1989. Os Passos da pesquisa. p. 29-64. (Série Princípios) 